\title{
Minha música em cena
}

Tom Tavares ${ }^{1}$

\section{Resumo}

O compositor discorre abreviadamente sobre a sua trajetória, enfatizando a frutífera relação com as artes cênicas, e disponibiliza fichas técnicas contendo nomes de todos os músicos que contribuíram para a materialização dos seus trabalhos destinados a peças teatrais e espetáculos de dança encenados na Bahia.

Palavras-chave: Compositor - peças teatrais espetáculos de dança

\section{Abstract}

The composer briefly talks about his career, emphasizing the fruitful relationship with the scenic arts, and make available the production credits, including names of all musicians who contributed to the materialization of his works intended for theatrical plays and dance performances exhibited in Bahia.

Composer - theatrical plays - dance performances

Meu curso de criação musical para Artes Cênicas começou quando eu tinha uns 9, 10 anos de idade, ainda na minha terra natal, Santana dos Brejos, então uma pequeníssima cidade de não mais que dois mil habitantes, localizada no velho oeste baiano. Aquilo era um mundo fechado, pedaço de terra fora do mundo, sem rio, sem estrada, sem caminho, sem luz. Sem teatro, sem cinema, sem artes, em suma. Se dança havia - quando havia - era de salão. Com a devida distância estabelecida pelo vigário.

É certo que sabíamos que havia um mundo além dali, mas não o saboreávamos. Para o santanense, cujo bairrismo o aproxima do santamarense, o mundo real era o mundo local. E bastava. $O$ resto era o resto do mundo, periferia orbitante.

Na memória que me resta, consta que o mundo só entrou em minha terra - banhada por um tênue e inconstante córrego - na forma de onda, ou melhor, através de ondas: ondas do rádio. Isso foi na segunda metade dos anos cinqüenta, com a chegada de um receptor, nobilíssimo ornamento pomposamente alçado ao centro da sala de jantar, alimentado por uma bateria de caminhão. Sem luz elétrica, quando a cidade escurecia no final da tarde o som do rádio brilhava, compondo a trilha sonora das noites sertanejas. E a imaginação voava.

Além do encantamento provocado pela transmissão das músicas do cancioneiro popular brasileiro, outro romance se estabelecia diante da descoberta de pontos no dia que levavam ao ar pérolas do rádio-teatro, também conhecidas como novelas radiofônicas. Fascinavam-me os enredos, as tramas, as interpretações. Mas, este deslumbramento se avultava a cada aplicação de efeitos sonoros, diante da audição das insubstituíveis canções-tema, confirmando um final feliz para o casamento das artes.

Na Rádio Nacional, eu ouvia novelas que apresentavam atmosfera interiorana, a exemplo de Jerônimo, O Herói Do Sertão, e outras, de ambientação urbana, cujo modelo eram $A s$ Aventuras Do Anjo. Na primeira, a sonoplastia destacava o ruído dos cascos dos cavalos, os sons dos carros de bois, dos pássaros, do vento, dos rios, dos trovões. Na segunda, além das buzinas, do ronco dos motores dos carros, do burburinho das ruas da cidade grande, o imaginário era colorido pela ação repetida da Matilde, metralhadora de um dos companheiros do personagem principal. Um pouco mais tarde, girando o botão sintonizador até a Rádio Tupi, era a vez de "assistir" às viagens siderais de Radar, O Homem Do Espaço, novela que se distinguia pela utilização de sons futuristas, produzidos eletronicamente. Assim, daquele admirável mundo novo o rádio ia me ensinando as mais preciosas lições de casa.

Quando, enfim, eu fui pro mundo, caí nas Minas Gerais, cheguei ao Rio de Janeiro, e acabei na Bahia: pecador na terra do Salvador. Nas Minas, fui roqueiro. No Rio, popular brasileiro. $\mathrm{Na}$ Bahia, disseram que eu era erudito. Problema deles: eu podia ser tudo ou nada disso, menos cada um apenas. Corria a metade dos anos setenta quando aqui cheguei, trazendo na

${ }^{1}$ Músico, compositor, prof. da Escola de Música da UFBA. 
bagagem uma guitarra, um violão, uma gaita cromática, alguns discos, algumas partituras e um velho gravador. $O$ resto era descartável.

Meu vestibular tinha na banca Ernst Widmer, Paulo Gondim, Lindembergue Cardoso e Piero Bastianelli. Quem teme, treme. Eu tremi, sim... mas, entrei. E foi ali mesmo, na Escola de Música da UFBA, que cedo travei contatos imediatos com todos os graus das demais artes. Sim, vale lembrar que, na época, ela era a Escola de Música e Artes Cênicas. Trocávamos figurinhas de todos os matizes nas aulas de Integração Artística, insubstituível disciplina ministrada por quatro professores: um de Música, um de Teatro, um de Dança e um de Artes Plásticas.

Aqui, abro um parêntesis para lembrar que, na soterópolis de então, havia dois nomes no ápice da produção musical para as Artes Cênicas: Lindembergue Cardoso e Fernando Cerqueira. Pra minha sorte, ambos foram meus professores de Composição. E não foi só isso: ambos estavam, naquele justo momento, se afastando das trilhas e caminhando para a quase exclusividade de dedicação à área musical, presumível exigência da vida acadêmica. Para que tal acontecesse, é possível que houvesse, também, outra razão: teatro dava trabalho, tomava muito tempo e pagava pouco. Assim, saem os mestres, entram os pupilos. E eu estava no ponto esperando o trem.

Eu estava no ponto, pronto pra começar, e fui chamado por Fernando Cerqueira para integrar o grupo de execução da sua música, escrita especialmente para Vertigem do Sagrado, uma produção de arte integrada dirigida por Lia Robatto e Luciano Diniz, apresentada no Solar do Unhão no mês de janeiro de 1977. Éramos quatro estranhos bruxos agitando um grande caldeirão de sons: Jayme Ledezma, Antonio José Isturain, Walmir Palma e eu. Cada ensaio, uma aula. Cada encenação, uma prova. Mais um bom curso na minha vida. $\mathrm{E}$, do lado de fora, ainda ouvia-se a boa música do Mar Revolto.

Quando janeiro acabou, Rufo Herrera outro nome de peso na elaboração de trilhas daquele período - precisava de alguém para dar seqüência ao seu trabalho musical na montagem de uma peça infantil chamada Joga Babico No Lixo. Apresentei-me. Lembro-me bem que foi à tarde: antes do ensaio, tivemos uma conversa em que ele expôs idéias acerca da aplicação da música na peça em questão e me mostrou uma pequena partitura contendo, apenas, a linha melódica. Delegou-me a harmonização e adequação à cena. Desejou-me boa-sorte e nunca mais o vi. Resultado: acabei criando o resto da parte sonora, assumindo a direção musical e executando, sozinho, ao vivo, todo o trabalho, valendo-me do meu velho violão, da gaita cromática e de alguns acessórios percussivos. Foi no tombo, como dizem os motoristas de carro sem motor de arranque ou com bateria descarregada. Mas, pegou.

Daí em diante, tornou-se impossível parar de trilhar: o teatro necessitava e eu gostava. Ou seja: necessitávamos os dois. Precisa mais?

Bom, chega de contar histórias. Coloquemos os números na ribalta, em pauta. A seguir, faço questão de deixar registradas informações básicas acerca de cada um dos 48 trabalhos de composição e direção musical para dança e teatro por mim realizados na Bahia (títulos, autores, diretores, locais e datas) destacando, agradecidamente, os nomes daqueles que dividiram comigo o prazer de sonorizar ações dramáticas, movimentos, emoções, sonhos: instrumentistas que concretizaram a harmonização entre as minhas fantasias musicais e a encantadora realização do imaginoso mundo das Artes Cênicas.

JOGA BABICO NO LIXO - Texto: Volker Ludwig // Direção: Gildásio Leite // Composição e Direção Musical: Rufo Herrera e Tom Tavares // Música ao Vivo: Tom Tavares (voz, violão, percussão) // Local: Teatro do ICBA - 1977.

MOVIMENTALIZAÇÃO - Concepção e Direção: Lia Robatto (Grupo Experimental de Dança) // Composição e Direção Musical: Tom Tavares // Música ao Vivo: Chiquinho Brandão (flauta), Efraim Cruz (violino), Dílson Peixoto (viola), Tom Tavares (voz, violão), Jaime Ledezma (violoncelo), Joel Moura (percussão), Carmen Lúcia Amorim (voz), Renato Aguiar (voz/percussão), Juarez Tavares (voz), Odeval Matos (voz), André Pelagio Bessa (voz) // Locais: Teatro Castro Alves - 1977

INSTANTE DE UMA CRUZADA Direção: Içara Dantas (Grupo Cruzada) // Coreografia: Grupo Cruzada // Composição e Direção Musical: Tom Tavares // Música ao 
Vivo: Chiquinho Brandão (flauta), Efraim Cruz (violino), Tom Tavares (voz, violão), Jaime Ledezma (violoncelo), Dílson Peixoto (viola), Juarez Tavares (voz), Joel Moura (percussão), Renato Aguiar (voz/percussão), Carmen Lúcia Amorim (voz), Odeval Matos (voz), André Pelagio Bessa (voz) // Local: TCA - 1977

VIA SACRA - Texto: Henri Ghéon // Direção: Manoel Lopes Pontes // Composição e Direção Musical: Tom Tavares // Música ao Vivo: Lino Neto (flauta, baixo) e Tom Tavares (voz, violão, teclado, canalha) // Local: Igrejas de Salvador - 1978.

MOBILIZAÇÃ̃o - Concepção e Direção: Lia Robatto // Composição e Direção Musical: Tom Tavares // Música ao Vivo: Oscar Dourado (flauta), Efraim Cruz (violino), Carmen Guadalupe (violino), Dílson Peixoto (viola), Lino Neto (guitarra), Jaime Ledezma (celo), Sarquis (baixo), Sérgio Guedes (piano), Afonso Silva (bateria), Jaime Sodré (bateria), Tom Tavares (voz, violão, regência) // Local: TCA - 1978

DON CHICOTE MULA MANCA E SEU FIEL COMPANHEIRO ZÉ CHUPANÇA Texto: Oscar Von Pfuhl // Direção: Manoel Lopes Pontes // Composição e Direção Musical: Tom Tavares // Música ao Vivo: Regina Cajazeira (flauta), Juracy Bemol (trompete), Renato Aguiar (violão), Jaime Sodré (bateria) // Locais: Auditório da Biblioteca Central e Teatro Castro Alves - 1978

DANÇA?! - Concepção, Direção e Execução: Lia Rodrigues, Lívia Serafim, Leda Muhana (Grupo Ecos) // Composição, Direção e Execução Musical ao Vivo: Chiquinho Brandão (flauta), Tom Tavares (violão), Jorge Amorim (percussão) // Local: Solar do Unhão - 1978

CHOQUE - Texto: Criação Coletiva (Luciano Diniz, Carlos Ribas, Eduardo Moraes, Era Encarnação, Maria de Fátima, Rita Crandon) // Direção: Luciano Diniz // Direção Musical: Tom Tavares // Composição: Caetano Veloso e Tom Tavares // Música Gravada (Estúdio Alcyvando Luz): Chiquinho Brandão (flauta), Tom Tavares (violão), Lino Neto (baixo), Jaime Sodré (bateria) // Local: Sala do Coro TCA- 1978
O ROMANCE DOS DOIS SOLDADOS DE HERODES - Texto: Osman Lins // Direção: Deolindo Checcucci // Composição e Direção Musical: Tom Tavares e Chiquinho Brandão // Música ao Vivo: Chiquinho Brandão (flauta), Renato Aguiar (violão) // Local: Teatro Santo Antônio - 1978

FAUSTO - Texto: Johann Wolfgang Von Goethe // Direção: Márcio Meirelles // Composição, Direção Musical e Gravação (Estúdio Alcyvando Luz): Chiquinho Brandão (flauta), Tom Tavares (violão) // Local: Sala do Coro do TCA - 1978

DOROTÉIA - Texto: Nelson Rodrigues // Direção: Deolindo Checcucci // Direção Musical: Tom Tavares e Chiquinho Brandão // Música Gravada (Estúdio EMUS): trilha criada a partir de gravações diversas // Local: Teatro SENACPelourinho - 1978

RENTE QUE NEM PÃO QUENTE - Texto: Gildásio Leite e Grupo Batalha // Direção: Gildásio Leite // Composição e Direção Musical: Tom Tavares // Música ao Vivo: Dominique Harry Smith (violão) // Local: diversas cidades da Bahia - 1978

NEGRO AMOR DE RENDAS BRANCAS Texto: Jurema Penna // Direção: Antônio Barretto // Direção Musical: Tom Tavares // Música Gravada (Estúdio EMUS): Tom Tavares (violão, percussão), Hans Ludwig (trompete, percussão), trilha incluindo gravações diversas // Local: Teatro Santo Antônio - 1978

MAIS QUERO UM ASNO QUE ME GARREGUE QUE GAVALO QUE ME DERRUBE" - Texto e Direção: Carlos Alberto Soffredini // Direção Musical: Tom Tavares // Composição: T. Tavares e Fábio Cintra // Música ao Vivo: $1^{a}$. Temporada: Chiquinho Brandão (flauta), Edu Nascimento (violão), Moisés Gabrielli (baixo), Jaime Sodré (bateria) // $\mathbf{2}^{\mathrm{a}}$. Temporada: Chiquinho Brandão (flauta), Tom Tavares (violão), Lino Neto (baixo), Raul Carlos Gomes (bateria) // Local: Sala do Coro do TCA $-1978$

BOCAS NO INFERNO - Texto: Cleise Mendes, Deolindo Checcucci // Direção: 
Deolindo Checcucci // Composição e Direção Musical: Tom Tavares // Música ao Vivo: Luciano Chaves (flauta), Edu Nascimento (guitarra), Moisés Gabrielli (baixo), Jaime Sodré (bateria) // Local: Circo Renascente - 1979

JOÃOZINHO E MARIA - Texto: Jacob e Wilhelm Grimm // Direção: Manoel Lopes Pontes // Composição e Direção Musical: Tom Tavares // Música Gravada (Estúdio EMUS): Lino Neto (flauta), Hans Ludwig (trompete), Tom Tavares (voz, violão, baixo, percussão), Jaime Sodré (bateria), Andréa Daltro (voz), Tereza Oliveira (voz) // Local: Teatro Castro Alves - 1979

ALICE - Texto: Lewis Carroll // Direção: Márcio Meirelles // Direção Musical: Tom Tavares // Música ao Vivo: criação e execução pelo elenco // Local: Sala do Coro do Teatro Castro Alves - 1979

SINA - Concepção e Direção: Lia Robatto (Grupo Experimental de Dança) // Composição e Direção Musical: Lindembergue Cardoso // Direção e Regência de Ensaios: Tom Tavares // Música ao Vivo: Sopranos: Andréa Daltro, Celina Lopes, Brasilena Trindade, Marilúcia Trindade, Tânia Morais, Zélia Barros; Contraltos: Carmen Guadalupe (clarineta), Guilhermina Andrade, Cândida Lobão (celo); Tenores: Keiler Rego, Renato Aguiar (percussão), Rui Figueiredo, Hans Ludwig (trompete), Efraim Cruz (violino); Baixos: Élcio Sá, Jaime Ledezma (celo), Roberto Williams, Tom Tavares (violão, percussão) Local: Teatro Castro Alves - 1979

DIA DE AUSÊNCIA - Texto: Douglas T. Ward // Direção: Floyd Gaffney // Composição e Direção Musical: Tom Tavares // Música ao Vivo: Juracy Bemol (trompete), Asa Branca (violão), Renato Aguiar (violão/percussão), Andréa Daltro (voz) // Local: Teatro Santo Antônio - 1979

LOCOMOC E MILIPILI - Texto: Rainer Hachfeld e Volker Ludwig // Direção: Gildásio Leite // Composição e Direção Musical: Tom Tavares // Música Gravada (Estúdio EMUS): Tom Tavares (voz / violão), Lino Neto (baixo), Jair Bala (bateria) // Local: Teatro do ICBA 1979
PORQUE O GIGANTE AZUL CHORA Texto: Ilo Krugli // Direção: Maria Idalina // Composição e Direção Musical: Tom Tavares // Música ao Vivo: Edu Nascimento (guitarra), Asa Branca (violão), Beca (percussão) // Local: TCA - 1979

\section{APESAR DE TUDO, A TERRA SE MOVE} - Texto: Bertold Brecht - Adaptação: Cleise Mendes, Conceição Castro, Paulo Dourado // Direção: Paulo Dourado // Composição e Direção Musical: Tom Tavares // Música Gravada (Estúdio IRDEB): Tom Tavares (violão, teclados, percussão, efeitos) // Local: TCA 1979

BAAL - Texto: Bertold Brecht // Direção: Márcio Meirelles // Composição e Direção Musical: Tom Tavares // Música ao Vivo: executada pelo elenco // Local: Sala do Coro do Teatro Castro Alves - 1980

\section{PONTO DE PARTIDA - Texto:} Gianfrancesco Guarnieri // Direção: Manoel Lopes Pontes // Composição e Direção Musical: Tom Tavares // Música ao Vivo: Luiz Henrique de Codes (flauta), Curinga (violão), Lino Neto (baixo), Espiga (percussão) // Local: Teatro Vila Velha - 1980

JOÃOZINHO E MARIA - Texto: Jacob e Wilhelm Grimm // Direção: Manoel Lopes Pontes // Composição e Direção Musical: Tom Tavares // Música Gravada (Estúdio Irdeb): Luciano Chaves (flauta), Tom Tavares (voz, violão, baixo, percussão), Jorge Brasil (bateria), Dina Tavares (voz) // Local: Teatro Vila Velha - 1981

QUASE COM CERTEZA - Direção: Betty Grebler e Leda Muhana (Grupo Tran-Chan) // Composição "Música da Marcha": Tom Tavares // Música Gravada (Estúdio IRDEB): Luciano Chaves (flauta), Tom Tavares (violão), Jaime Sodré (bateria) // Locais: Teatro Santo Antônio e Sala do Coro do Teatro Castro Alves - 1981

O PAI - Texto: August Strindberg // Direção: Márcio Meirelles // Composição e Dir. Musical: Tom Tavares // Música ao Vivo: Grupo Anticália // Local: TCA - 1981

MARIA QUITÉRIA - Coreografia e Direção: Antonio C. Cardoso (Cia. De Dança Balé TCA) / 
/ Composição e Dir. Musical: Tom Tavares // Música Gravada (Reitoria UFBA Equipamentos: Estúdio WR): Oscar Dourado (flauta), Klaus Haefele (clarineta), Francisco Assis (fagote), Juracy Bemol (trompete), Fernando Santos (percussão), Fernando Mascarenhas (percussão), Ana Margarida (violino), Georgina Lemos (violino), Roberto Urpia (viola), Paulo Costa Lima (violoncelo), Leonardo Boccia (violão), Erick Vasconcelos (regente) // Locais: TCA - 1981, Teatro da Paz (Belém), Teatro Amazonas (Manaus), Teatro José de Alencar (Fortaleza), Teatro Alberto Maranhão (Natal), Ginásio Geraldo Magalhães (Recife), S. Cristóvão (Sergipe), Teatro PUC (P. Alegre), Teatro Guaíra (Curitiba), Teatro Municipal (São Paulo), Palácio das Artes (B. Horizonte), Teatro Nacional (Brasília), Teatro João Caetano (Rio) - 1982

O JARDIM DAS BORBOLETAS - Texto: André Adler // Direção: Echio Reis // Direção Musical: Arthur Andrade e Magno Aguiar // Composição: Arthur Andrade, Magno Aguiar, Tom Tavares // Música Gravada (Estúdio IRDEB): Magno Aguiar (acordeom), Arthur Andrade (violão), Lino Neto (baixo elétrico), Gun (bateria) // Local: Teatro Vila Velha - 1981

RAPUNZEL - Adaptação: Cleise Mendes e Márcio Meirelles // Direção: Márcio Meirelles // Direção Musical: Tom Tavares // Composição: Diversos Autores // Música ao Vivo: Grupo Anticália // Local: Teatro do ICBA - 1981

O PATINHO FEIO - Texto: Maria Clara Machado // Direção: Manoel Lopes Pontes // Composição e Direção Musical: Tom Tavares // Música Gravada (Estúdio IRDEB): Luciano Chaves (flauta), Tom Tavares (voz, violão, baixo, percussão), Analívia Grimaldi (voz), Jane Cavazine (voz), Socorro Medeiros (voz), Ana Paula (voz), Agnaldo Lopes (voz)// Local: Teatro Castro Alves - 1982

FOLIA - Concepção, Direção e Execução: Grupo de Dança Contemporânea da UFBA // Direção Musical: Tom Tavares // Composição: Hermeto Pascoal, Egberto Gismonti, Carlos Lyra, Aécio Flávio e Tom Tavares // Música "Saída e Asneiras", de Tom Tavares, Gravada
(Estúdio IRDEB): Tom Tavares (violão, percussão) // Local: Teatro Santo Antônio 1982 e 1983

CINÉTICA - Concepção, Direção e Execução: Catarina Laborda e Reginaldo Flores (Grupo Cine) // Composição e Direção Musical: Tom Tavares // Música "Fantasias" Gravada (Estúdio WR): Luciano Chaves (flauta), Tom Tavares (voz, violão), Anunciação (percussão) // Local: Sala do Coro do Teatro Castro Alves $-1982$

MACBETH - Texto: William Shakespeare // Direção: Márcio Meirelles // Composição e Direção Musical: Tom Tavares // Música ao Vivo: executada pelo elenco // Local: Teatro Castro Alves - 1982

SIMUN - Texto: August Strindberg// Direção: Márcio Meirelles // Composição e Direção Musical: Tom Tavares // Música ao Vivo: Bárbara Vasconcelos (flautas), Celso Aguiar (violão), Cândida Lobão (violoncelo), Romeu Rezende (percussão) // Local: Teatro Santo Antônio - 1983

TEM CARDUME NO MEU AQUÁRIO Texto: Miriam Fraga e Charanga Lítero-Musical Amigos de Pagu // Direção: Márcio Meirelles // Direção Musical: Tom Tavares // Composição: Tom Tavares e Charanga Lítero-Musical Amigos de Pagu // Música ao Vivo: Tota Portela (flauta), Eduardo Torres (piano), Ivan Bastos (baixo), Ivan Huol (bateria) // Local: Circo Troca de Segredos - 1984

\section{A COMPANHIA DAS ÍNDIAS - Texto:} Nelson de Araújo // Direção: José Reynaldo // Direção Musical: Tom Tavares // Música Gravada: Trilha criada a partir de gravações diversas // Local: Teatro Vila Velha - 1984

JOÃOZINHO E MARIA - Texto: Jacob e Wilhelm Grimm // Direção: Manoel Lopes Pontes // Direção Musical e Composição: Tom Tavares // Música Gravada (Estúdio Corsário): Ulyses Factum (teclados), Miltinho (baixo), Augusto Papamel (bateria), Dina Tavares (voz) // Local: Cine-Teatro Nazareth - 1986

NO GALOPE DO RISO, IMPROVISO Texto: Cordel adaptado por Cleise Mendes e 
Roberto Wagner Leite (Ticão) // Direção: Roberto Wagner Leite // Direção Musical: Magno Aguiar // Composição: Tom Tavares // Música Gravada (Teatro IRDEB - Equipamentos: Estúdio IRDEB): Domingos Moraes (sanfona), Espiga (percussão), Beca (percussão) // Local: Teatro Santo Antônio - 1987

FEIO NÃO TEM CARÁTER - Texto: Aninha Franco // Direção: Ewald Hackler // Direção Musical: Tom Tavares // Composição: Diversos Autores (Anos 60) // Música ao Vivo: Tom Tavares (voz, violão) // Local: Teatro do ICBA - 1987

COISAS E COISAS - Texto: Adaptação de Márcio Meirelles e Maria Eugênia Millet de "POR QUE OS TEATROS ESTÃO VAZIOS" (Karl Valentin) e "MATEUS E MATEUSA" (Qorpo-Santo) // Direção: Maria Eugênia Millet // Direção Musical: Tom Tavares // Música ao Vivo: Criação e execução pelo elenco // Local: TCA - 1988

É UMA BRASA, AMORA - Texto: José Antonio Moreno // Direção: J. A. Moreno / Shirley Pinheiro // Direção Musical: Tom Tavares // Composição: Diversos Autores (J.Guarda) // Música Gravada (Estúdio Tapwi'n): Sérgio Henriques (teclados) Paulo Costa (guitarra), Moisés Gabrielli (Baixo), Chico Costa (bateria) // Local: TCA - 1989

o PATINHo FEIO - Texto: Maria Clara Machado // Direção: Manoel Lopes Pontes // Composição e Direção Musical: Tom Tavares // Música Gravada (Estúdio Tapwi'n): Tom Tavares (voz, teclados, violão, baixo, percussão), Dina Tavares (voz), Marta Cirne (voz) // Local: Cine Teatro Nazaré -1991

\section{A CONSPIRACÃO DOS ALFAIATES -}

Texto: Aninha Franco, Cleise Mendes, Paulo Dourado // Direção: Paulo Dourado // Composição e Direção Musical: Tom Tavares e Cacau Celuque // Música Gravada (Estúdios Tapwi'n): Tom Tavares (voz, violão, teclado, arranjos para coro), Cacau Celuque (teclados, programação de teclados,arranjo para coro) // Música ao Vivo: Cacau Celuque (teclados), Tostão (percussão) // Locais: Campo Grande e Teatro Castro Alves - 1992 e 1993
CANUDOS - Texto: Aninha Franco e Cleise Mendes // Direção: Paulo Dourado // Composição e Direção Musical: Tom Tavares e Cacau Celuque // Música Gravada (Estúdios Tapwi'n): Tom Tavares (violão, teclados), Cacau Celuque (teclados) // Locais: Ginásio SESI (Retiro), Ginásio SESI (Itapagipe), Concha Acústica TCA - 1993

REI BRASIL 500 ANOS: UMA ODISSÉIA TROPICAL (Ópera) - Autores: Fernando Cerqueira, José Carlos Capinan, Paulo Dourado // Direção: Paulo Dourado // Direção Musical do Núcleo de Música Popular: Tom Tavares // Arranjos: Tom Tavares ("Manda Chamar", "Noiva Brasileira"), Fred Dantas ("Rei Brasil") e Ângelo Castro ("Em Nome de Deus") // Músicos: cantores Lazzo, Margareth Menezes, Carla Visi e Roberto Mendes, Gerônimo (trombone), Danilo Santana (teclados), Tom Tavares (teclados), Alex Mesquita (guitarra), Leonardo Caribé (viola), Gustavo Caribé (baixo), Walmar Paim (bateria), Cláudio Badega (percussão), Ori (percussão) e Orquestra Sinfônica da UFBA, regência de Pino Onnis // Local: Concha Acústica do TCA - 2000

O ABAJOUR LILÁS - Texto: Plínio Marcos // Direção: Manoel Lopes Pontes // Composição e Direção Musical: Tom Tavares // Música Gravada (Estúdio Nov9mbro): Tom Tavares (voz, violão, guitarra, teclados, baixo, percussão, efeitos), Hermógenes Araújo (percussão) // Local: Sala do Coro do TCA - 2002

OS IKS - Texto: Collin Turnbull // Direção: Francisco Medeiros // Composição e Direção Musical: Tom Tavares // Música Gravada (Estúdio Palco Livre): Tom Tavares (voz, flauta doce, violino, violão, teclados, percussão, efeitos) // Local: Sala do Coro do TCA - 2002/2003

Tom Tavares - Violonista, compositor, regente, professor da Escola de Música da UFBA, roteirista do programa Música dos Mestres, roteirista e apresentador do programa Outros Baianos, coordenador do Festival de Música Educadora FM. 